\title{
Nutritional Status and Disease Profile of Under Five Children in a Selected Rural Area
}

\author{
Sultana $N^{1}$, Debnath $S^{2}{ }^{2}$, Sultana $R^{3}$, Akter $S^{4}$, Banu DS ${ }^{5}$, Khatun $\mathrm{M}^{6}$
}

\begin{abstract}
Introduction: Malnutrition is referred to as the greatest single threat to the world's public health, especially for the developing countries. Childhood malnutrition is linked to slower cognitive development and serious health impairments later in life that reduce the quality of life of individuals. Nutritional status is determined anthropometrically and is a significant determinant of various types of morbidity and is associated with an increased risk of death from acute respiratory infection, diarrhoea, measles and few other infectious diseases.
\end{abstract}

Objective: To assess nutritional status and disease profile of under five children in a rural area of Bangladesh.

Materials and Methods: This cross-sectional study was conducted among 205 children with age between 1 to 59 months who were selected purposively. Two hundred five data were collected by interviewing the mothers of the children and also by reviewing the documents using a pretested semi-structured questionnaire and checklist. Nutritional status was assessed using WHO recommended Z-score category and Mid Upper Arm Circumference measurement.

Results: Out of 205 children, more than half (57.6\%) were girls and the rest of them were boys. About two-third of the children were aged between 25 and 59 months. Maximum (40.5\%) mothers of the children had a background of secondary educational status and most of them $(90.2 \%)$ were housewives. More than one-third $(36.1 \%)$ of the respondents belong to families haveing monthly income between Tk. 5001 and 10,000 and the average income was Tk.14,544. About onethird $(33.5 \%)$ of the children were stunted in Height for Age Z score. While $9.7 \%$ were moderately wasted and $1.5 \%$ were severely wasted in Weight for Height $Z$ score. $3.8 \%$ of the children were severely underweight and $70.8 \%$ of the children's weight was within the normal limit for their age. By Mid Upper Arm Circumference (MUAC) measurement, about 20.0\% were of moderate acute malnutrition (MAM) and $1.1 \%$ were of severe acute malnutrition (SAM). Among the associated morbidities, diarrhoeal disease had highest prevalence ( $45 \%$ ) followed by respiratory tract infection (38\%) and pneumonia (18\%).

Conclusion: Under five children are the vulnerable segment of the population. The result demonstrates a high prevalence of malnutrition (especially stunting) among under five children in the study area. Considering the acute and long-term consequences of malnutrition, interventions aiming at reducing child malnutrition in such a population should focus on all the children of less than 5 years of age.

Key-Words: Anthropometric measurement, Disease profile, Under five children, Z-score.

\begin{abstract}
Introduction
Adequate nutrition during infancy and early childhood is fundamental to the development of child's full human potential ${ }^{1}$. It is well recognized that the period from birth to two years of age is a "critical window" for the promotion of optimal growth, health, and behavioral development ${ }^{2}$. Poor nutrition leads to ill-health and ill-health contributes to further deterioration in nutritional status $^{1,2}$. Approximately 12 million children younger than 5 years of age die every year in developing countries. Leading cause of death is diarrhoea and acute respiratory tract (ART) infection. More than $50 \%$ of these deaths are attributed to diarrhoea, acute respiratory
\end{abstract}

1. Dr Nasrin Sultana, MBBS, MPH, Asst Professor of Community Medicine, Shadeed Tajuddin Ahmad Medical College, Gazipur 2. Dr Sumon Chandra Debnath, MPH (NIPSOM), District Trainer, National Institute of Preventive and Social Medicine (NIPSOM), Mohakhali, Dhaka 3. Dr Rifat Sultana, MBBS, FCPS, Asst Professor of Gynae \& Obs, Shadeed Tajuddin Ahmad Medical College, Gazipur 4. Shamina Akter, Senior Staff Nurse, Upazila Health Complex, Vhuapur, Taingail 5. Dr Dewan Shahida Banu, MBBS, DGO, Asst Professor of Gynae \& Obs, Shadeed Tajuddin Ahmad Medical College, Gazipur 6. Dr Mahmuda Khatun, MBBS, FCPS, Asst Professor of Gynae \& Obs, Shadeed Tajuddin Ahmad Medical College, Gazipur. 
illness, malaria or measles, conditions that are either preventable or treatable with low-cost interventions ${ }^{3}$. Although malnutrition is prevalent in developing countries, it is rarely cited as being among the leading causes of death ${ }^{2-3}$.

In the early 1990s, Pelletier and colleagues used a different approach to estimating the contribution of malnutrition to all-cause mortality in children ${ }^{4}$. Their analytical framework took the underlying causes of death into account and it suggested that malnutrition (measured as poor anthropometric status) was an associated cause in about half of all deaths occurring among children in developing countries ${ }^{4,5}$. Although the association between malnutrition and mortality are well documented, the association between malnutrition and mortality attributed to specific causes is less well described. If malnutrition does not increase the risk of mortality from all causes of death equally, intervention programs that succeed in improving nutritional status may not have the same potential for reducing children's mortality in regions with different disease profiles ${ }^{6}$.

The synergistic relation between malnutrition and infection is well known, and nutritional interventions have been recognized as an important approach for reducing mortality from acute respiratory illness and diarrhoea ${ }^{7}$. The WHO Integrated Management of Childhood IIIness initiative is based on the premise that combining efforts to promote the appropriate case-management of serious infectious diseases with nutritional interventions, immunization programs and other disease prevention and health promotion activities will be more effective in decreasing child mortality than implementing any one of the components alone ${ }^{8-9}$.

Infectious diseases remain the most important immediate cause of death and disability among children world-wide ${ }^{6}$. The burden of ill-health associated with these conditions is especially high in developing countries. Despite the progressive rise in chronic diseases as important causes of mortality, the epidemiological transition that is under way in the developing world does not reduce the need to continue investigating appropriate strategies for reducing child mortality from infectious diseases. In fact, these developments will make dealing with the unfinished agenda of mortality from infectious diseases, even more of a challenge ${ }^{7,9}$.
A number of studies carried out during an emergency and non-emergency situations have demonstrated the association between increased mortality and increasing severity of anthropometric deficits. Data from six longitudinal studies on the association between anthropometric status and mortality of children aged between 6-59 months revealed a strong association between the severity of weight-for-age deficits and mortality rates ${ }^{10}$.

The most commonly collected indicators of nutritional status are the anthropometric measurements of children of under five years of age. Children are more vulnerable to infection and their rapid rate of growth is easily affected by poor nutrition, thus measure of children's nutritional status is a good barometer of overall community health ${ }^{11}$. Therefore this study was undertaken to assess the nutritional status and disease profile of under five children.

\section{Materials and Methods}

This cross-sectional study was conducted to determine the level of nutritional status and disease profile of under five children. The study was conducted in Upazila Health Complex (UHC) Vhuapur, Taingail during the period of January to December 2015. Total 205 under-five children were selected by a purposive sampling method on the basis of defined selection criteria. The World Health Organization recommended height for age, weight for age and height for weight Z-score was used to assess the nutritional status of the children ${ }^{12}$. Mid Upper Arm Circumference (MUAC) also used to assess the nutritional status of the children. Morbidity pattern of the children was identified by reviewing the related documents. The research instrument was a pre-tested semi-structured questionnaire and one checklist. Data were collected by face to face interview with the mothers of the children following questionnaire. Before starting data collection, institutional permission from concerned authorities was taken. As the research participants were not vulnerable, the procedures followed for this study were in accordance with the CIOMS (Council for International Organizations of Medical Sciences) guidelines. After data collection, it was checked and verified. Data were analyzed by using both Statistical Package for Social Sciences (SPSS) version 20 and WHO Anthro Plus. Informed written consent was taken from the parents or children's legal guardian considering all ethical issues. Confidentiality was maintained regarding both verbal and documentary data. 


\section{Results}

Table-I: Socio-demographic characteristics of the study subjects $(n=205)$

\begin{tabular}{|c|c|c|}
\hline Characteristics & Frequency & $\%$ \\
\hline \multicolumn{3}{|l|}{ Age of the Subjects } \\
\hline 1-12 months & 35 & 17.1 \\
\hline 13-24 months & 37 & 18.0 \\
\hline 25-59 months & 133 & 64.9 \\
\hline \multicolumn{3}{|c|}{ Gender of the Subjects } \\
\hline Boys & 118 & 57.6 \\
\hline Girls & 87 & 42.4 \\
\hline \multicolumn{3}{|l|}{ Mother's age } \\
\hline 18-25 years & 116 & 56.6 \\
\hline $26-30$ years & 54 & 26.4 \\
\hline 31-35 years & 29 & 14.1 \\
\hline 36 and above & 6 & 2.90 \\
\hline \multicolumn{3}{|l|}{ Mother's education } \\
\hline Illiterate & 40 & 19.5 \\
\hline Primary & 68 & 33.2 \\
\hline Secondary & 83 & 40.5 \\
\hline Higher secondary & 6 & 2.90 \\
\hline Graduate & 5 & 2.40 \\
\hline Madrasha & 3 & 1.50 \\
\hline \multicolumn{3}{|c|}{ Monthly family income } \\
\hline Up to 5,000 taka & 26 & 12.7 \\
\hline $5,001-10,000$ taka & 74 & 36.1 \\
\hline 10,001-15,000 taka & 49 & 23.9 \\
\hline $15,001-20,000$ taka & 26 & 12.7 \\
\hline Above 20,001taka & 30 & 14.6 \\
\hline
\end{tabular}

Table-I depicts the socio-demographic characteristics of study population. Out of 205 children, most (64.9\%) of children were in the age group of 25 to 59 months. About $57.6 \%$ of the study population comprised of boys and $42.4 \%$ were girls. Among the total of 205 mothers, more than half $(56.6 \%)$ were in the age group between 18-25 years; minimum age was 18 years and the maximum was 38 years. Regarding mother's educational background, maximum $(40.5 \%)$ were of secondary educational level followed by primary $(33.2 \%)$ and illiterate $(19.5 \%)$. The average $( \pm S D)$ monthly family income was Tk. 14,544.4 $\pm 1,086.5$ and more than one-third (36.1\%) of the respondent's monthly family income was between Tk. 5001-10,000 and about one-fourth $(23.9 \%)$ respondent's monthly family income was between Tk.10001-15,000 (Table-I). Among 205 children, maximum (66.5\%) children were normal in height for age, followed by $21.2 \%$ who were moderately stunted and $12.3 \%$ were severely stunted (Table-II).

Table-II: Distribution of the children by height for age category (Stunting) $(n=205)$

\begin{tabular}{|l|c|c|}
\hline Height for Age Category (Stunting) & Frequency & $\mathbf{\%}$ \\
\hline Normal $(\geq-1$ SD to +2 SD ) & 136 & 66.5 \\
\hline Mild Stunting ( $\geq-2$ SD to <-1 SD) & 44 & 21.2 \\
\hline Moderate Stunting ( $\geq$-3 SD to <-2 SD) & 25 & 12.3 \\
\hline
\end{tabular}

Out of the total 205 children, maximum (70.8\%) of the children's weight was within the normal limit for their age followed by $16.1 \%$ children who were mildly underweight, 9.3\% children were moderately underweight and 3.8\% were severely underweight (Table-III).

Table-III: Distribution of the children by weight for age category (Underweight) $(n=205)$

\begin{tabular}{|l|c|c|}
\hline Weight for Age Category (Underweight) & Frequency & $\mathbf{\%}$ \\
\hline Normal $(\geq-1$ SD to +2 SD ) & 145 & 70.8 \\
\hline Mild Underweight $(\geq-2$ SD to <-1 SD) & 33 & 16.1 \\
\hline Moderate Underweight ( $\geq$-3 SD to <-2 SD) & 19 & 9.3 \\
\hline Severe Underweight (<-3 SD) & 8 & 3.8 \\
\hline
\end{tabular}

Among the total 205 children, maximum (87.3\%) children were normal in height for weight category followed by 9.7\% children who were moderately wasted (Moderate Acute Malnutrition-MAM), 1.5\% were overweight and only $1.5 \%$ children were severely wasted (Severe Acute Malnutrition-SAM) in height for weight category (Table-IV).

Table-IV: Distribution of the children by height for weight category (Wasting) $(n=205)$

\begin{tabular}{|l|c|c|}
\hline Height/Length for Weight Category (Wasting) & Frequency & $\%$ \\
\hline Overweight $>+2$ SD) & 3 & 1.5 \\
\hline Normal $(\geq-2$ SD to $\leq+2$ SD) & 179 & 87.3 \\
\hline Moderate Wasting (MAM) ( $\geq$-3 SD to <-2 SD) & 20 & 9.7 \\
\hline Severe wasting (SAM) (<-3SD) & 3 & 1.5 \\
\hline
\end{tabular}

Among the total 205 children, age of 19 children was below 6 months and therefore excluded from MUAC measurement. Hence 186 children were included for MUAC measurement. Out of 186 children, maximum $(79.0 \%)$ children were normally nourished in MUAC measurement followed by $19.9 \%$ children who were having moderate acute malnutrition (MAM) and only $1.1 \%$ were of severe acute malnutrition (SAM) in MUAC measurement (Table-V). 
Table-V: Distribution of children by MUAC measurement $(n=186)$

\begin{tabular}{|l|c|c|}
\hline Mid Upper Arm Circumference (MUAC) & Frequency & $\mathbf{\%}$ \\
\hline Normal $(\geq 12.5 \mathrm{~cm})$ & 147 & 79.0 \\
\hline MAM $(11.5$ to $12.4 \mathrm{~cm})$ & 37 & 19.9 \\
\hline SAM $(\leq 11.4 \mathrm{~cm})$ & 2 & 1.1 \\
\hline
\end{tabular}

Among the 205 children, most prevalent disease $(45.0 \%)$ was diarrhoeal disease followed by respiratory tract infection (32.0\%), pneumonia (18.0\%), febrile disease $(6.0 \%)$, tonsillitis $(5.0 \%)$, scabies $(2 \%)$, otitis media $(1.3 \%)$ and protein energy malnutrition was $(0.9 \%)$ (Table-VI).

Table-VI: Distribution of the children by disease pattern

\begin{tabular}{|l|c|c|}
\hline Disease pattern* $^{*}$ & Frequency & \% \\
\hline Diarrhoeal disease & 97 & 45.0 \\
\hline Pneumonia & 37 & 18.0 \\
\hline Respiratory Tract Infection & 65 & 32.0 \\
\hline Febrile Disease & 12 & 6.0 \\
\hline Tonsillitis & 6 & 5.0 \\
\hline Scabies & 5 & 2.0 \\
\hline Otitis Media & 3 & 1.3 \\
\hline Protein Energy Malnutrition & 2 & 0.9 \\
\hline
\end{tabular}

*Multiple responses

\section{Discussion}

The World Health Organization working group's report on measuring the nutritional status of children recommends the use of Z-scores system as they have significant advantages over other approaches ${ }^{12}$. In brief, Z-scores indices are linear, sex independent and allow for further computation of summary statistics such as means and standard deviations to directly classify a population's nutritional status ${ }^{13}$.

It was a cross-sectional study conducted among 205 children of under 5 years of age. With age ranging between completed 1-59 months, 118 of them were girls and 87 were boys. The study provides anthropometric data on the nutritional status of under-five children as well as different disease patterns of the children. Mother's educational level was low with $19.5 \%$ of mothers being illiterate. Family income $(36.1 \%)$ was between Tk. 5,001-10,000 per month for the majority of the parents which cannot ensure proper health and nutrition to a medium size family in our country. These socio-demographic shreds of evidence provide enough reasons to consider that our study subjects belong to low socio-economic status. The present study results revealed that the total prevalence of stunting, wasting and underweight were $33.5 \%, 11.2 \%$ and $13.1 \%$, respectively of which $12.3 \%, 9.7 \%$ and $9.3 \%$ of children were moderately stunted, wasted and underweight respectively.
These findings indicate that the severity of stunting and underweight are within a very high range and wasting has a high prevalence rate, according to WHO-classification ${ }^{14}$ which confirm that malnutrition is a serious public health problem ${ }^{15}$.

The current study finding regarding prevalence of stunting $(33.5 \%)$ is lower than that of national figure ${ }^{16}$. This may be due to purposive sampling and small study area coverage. A study conducted by Rahman and Biswas in Bangladesh found that $44.0 \%$ children were stunted ${ }^{17}$; this finding is inconsistent with the present study finding. Another study ${ }^{18}$ in Chittagong Hill Tract showed that the prevalence of underweight was $48.0 \%$. This finding is also dissimilar with the present study finding.

In this study, it was found that $13.1 \%$ of under-five children were underweight. The present study findings regarding prevalence of underweight $(13.1 \%)$ among unde- 5 children was lower than the national figure $(33.0 \%)$ of Bangladesh ${ }^{16}$. This may be due to small sample size and purposive sampling technique. A multi-stage cross-sectional study done in Vietnam ${ }^{19}$ also revealed that the prevalence of underweight was found to be $31.8 \%$. The difference from present study may be due to variation in characteristics and level of progress. A study conducted by Rahman and Biswas in Bangladesh found that $47.0 \%$ children were underweight ${ }^{17}$. This finding is inconsistent with the present study findings.

In the study, the overall prevalence of wasting was $11.2 \%$. The current finding of wasting $(11.2 \%)$ is almost equivalent to the national figure $(14.0 \%)$ of Bangladesh $^{16}$. This might be due to the same socio-cultural and demographic characteristics of the children. A cross-sectional study conducted in Bangladesh found that the prevalence of wasting was $10.0 \%$ which was almost equal to the present study finding. Another cross-sectional study conducted by Avachat et al revealed that 15.7\% children were wasted ${ }^{20}$. There was a dissimilarity between these findings and the present study finding. A cross sectional community based survey was conducted among 15408 children under 5 years of age in $\operatorname{Iran}^{21}$. The rates of stunting, underweight, and wasting were $9.5 \%, 9.6 \%$, and $8.2 \%$, respectively. These findings are lower than that of the present study findings. 
In a study from India, it was shown that the overall prevalence of underweight, stunting, and wasting was $63.7 \%, 47.8 \%$ and $32.7 \%$ respectively ${ }^{22}$. Above findings of nutritional status are higher than that of the present study findings which may be due to regional variation and socio-economical influences.

Available evidence shows that MUAC is the best (i.e. in terms of age independence, precision, accuracy, sensitivity, and specificity) case detection method for severe and moderate malnutrition and that it is also simple, cheap and acceptable ${ }^{23}$.

The present study stated that 19 children's ages were below 6 months, therefore were excluded from MUAC measurement. Hence 186 children were included in MUAC measurement and out of them, maximum $(79.0 \%)$ children were found normally nourished followed by $19.9 \%$ children who had moderately acute malnutrition and only $1.1 \%$ were of severe acute malnutrition.

In a cross-sectional study ${ }^{24}$ in West Bengal of India, MUAC was measured using standard technique among 2028 children. The age-combined rates of overall (moderate and severe) undernutrition among boys $(38.49 \%)$ was higher than among girls $(32.22 \%)$. The age combined rates of moderate undernutrition were $36.34 \%$ and $31.03 \%$ among boys and girls, respectively. The rates of severe undernutrition were $2.15 \%$ and $1.20 \%$ among boys and girls, respectively. There were sex differences in both moderate and severe undernutrition. Above findings are inconsistent with the current MUAC measurement in this study.

It was noted in the present study that the majority $(45.0 \%)$ of the children were suffering from one or multiple episodes of diarrhoea followed by respiratory tract infection $(32.0 \%)$ and pneumonia (18.0\%). This is similar to the findings of Bhavsar et $\mathrm{al}^{25}$. A study conducted by Gupta in Punjab had found that $46.0 \%$ of under five children with diarrhoea suffered from malnutrition $^{26}$. Bisai et al reported that children with prevalent morbidities like diarrhea, ARI or measles were more likely to be under-nourished ${ }^{27}$. In another study conducted by Thakur in India found that upper respiratory tract infection $(21.6 \%)$ and diarrhoea $(18.2 \%)$ were the most commonly reported morbidities $^{28}$.
Above findings are inconsistent with the present study findings. The higher prevalence of diarrhoea and other communicable diseases could be due to poor environmental conditions, improper cooking practices, overcrowding etc.

\section{Conclusion}

The child growth monitoring is a good indicator of nutritional status of both the individual and the community. The present study revealed a high prevalence of stunting among the under-five children. The study also concludes that diarrhoeal diseases and respiratory tract infections are common among the children of under-five years of age. The Government, development partners, non-government organizations, and experts have to work in concert to improve the basic and effective nutrition interventions including exclusive breastfeeding, appropriate complementary feeding, supplementation of micronutrients to children, management of severe acute malnutrition, deworming and hygiene interventions coupled with those that address more structural causes and indirectly improve nutrition.

\section{References}

1. World Health Organization. The optimal duration of exclusive breastfeeding: Report of an expert consultation. Geneva: World Health Organization, Department of nutrition for health and development and department of child and adolescent health and development, 2001.

2. World Health Organization. Global strategy for infant and young child feeding. The optimal duration of exclusive breastfeeding. Geneva: World Health Organization, 2001.

3. UNICEF. The state of the world's children. New York, Oxford University Press, 1998.

4. Pelletier DL et al. A methodology for estimating the contribution of malnutrition to child mortality in developing countries. Journal of Nutrition 1994; 124:2106-22.

5. Schroeder DG, Brown KH. Nutritional status as a predictor of child survival: summarizing the association and quantifying its global impact. Bulletin of the World Health Organization 1994; 72:569-79.

6. World Health Organization: Infant and young child feeding (IYCF) Model Chapter for textbooks for medical students and allied health professionals. Switzerland: World Health Organization, 2009.

7. Jamison D. Disease control priorities in developing countries. New York, Oxford University Press, 1993.

8. Lambrechts T, Bryce J, Orinda V. Integrated management of childhood illness: a summary of first experiences. Bulletin of the World Health Organization 1999; 77:582-94. 
9. Van den Broeck J, Eeckels R, Vuylsteke J. Influence of nutritional status on child mortality in rural Zaire. Lancet 1993; 341:1491-5.

10. Allen LH. Nutritional influences on linear growth: A general review. European Journal of Clinical Nutrition 1994; 48:S75-S89.

11. Mengistu K, Alemu K, Destaw B: Prevalence of malnutrition and associated factors among children aged 6-59 months at Hidabu Abote District, North Shewa, Oromia Regional State. J Nutr Disorders Ther 2013; 1:1-15.

12. World Health Organization. Child growth standards: length/height-for-age, weight-for-age, weight-for-length, weight-forheight and body mass index-for-age: Methods and development, Geneva: World Health Organization, 2006.

13. Rahman A. and Chowdhury S. Determinants of Chronic Malnutrition among Pre-school Children in Bangladesh. Journal of Biosocial Science 2007; 39(2):161-73.

14. Gorstein J, Sullivan K, Yip R. Issues in the Assessment of Nutritional Status Using Anthropometry. Bulletin of the World Health Organization 1994; 72(2):273-83.

15. World Health Organization. Global Database on Child Growth and Malnutrition, Geneva: World Health Organization 1997.

16. National Institute of Population Research and Training (NIPORT), Mitra and Associates, and ICF International. Bangladesh Demographic and Health Survey 2014: Key Indicators. Dhaka, Bangladesh, and Rockville, Maryland, USA: NIPORT, Mitra and Associates, and ICF International, 2015.

17. Rahman A and Biswas SC. Nutritional status of under-5 children in Bangladesh. South Asian Journal of Population and Health 2009; 2(1):1-11.

18. Akhter N, Torlesse H, Pee Sde et al. Nutritional Status of Young Children and Their Mothers in Chittagong Hill Tracts, Bangladesh. Journal of Biosocial Science 2003; 57:172.
19. Hien NN, Kam S. Nutritional status and the characteristics related to malnutrition in children under five years of age in Nghean, Vietnam. J Prev Med Public Health 2008; 41:232-40.

20. Avachat SS, Phalke VD, Phalke DB; Epidemiological study of malnutrition (under-nutrition) among under five children in a section of rural area. Pravara Med Rev 2009; 1(2):20-2.

21. Kavosi1 E, Rostami1 ZH, Kavosi1 Z et al. Prevalence and determinants of under-nutrition among children under six: $A$ cross-sectional survey in Fars province, Iran. Int J Health Policy Manag 2014; 3(2):71-6.

22. Bisai S, Bose K, Dikshit S. Under-nutrition among slum children aged 3-6 years in Midnapore town, India. The Internet Journal of Biological Anthropology 2009; 2(2):26-9.

23. Myatt M, Khara T, Collins S. A review of methods to detect cases of severely malnourished children in the community for their admission into community-best therapeutic care programs. Food and Nutr Bull 2006; 27(3):S7-S23.

24. Biswas S, Bose K, Mukhopadhyay A et al. Mid upper Arm Circumference Based Under nutrition among Bengalee Children of Chapra, West Bengal, India. Iran J Pediatr 2010; 20(1):63-8.

25. Bhavsar S, Hemant M, Kulkarni R. Maternal and environmental factors affecting the nutritional status of children in Mumbai urban slum. Int J Sci Res 2012; 2:1-9.

26. Gupta A. Study of the prevalence of diarrhoea in children under the age of 5 years: It's association with wasting 2014 . Indian J Sci Res 2014; 7:1315-8.

27. Bisai S, Mahalanabis D, Sen A et al. Maternal education, reported morbidity and number of siblings are associated with malnutrition among Lodha preschool children of Paschim Medinipur, West Bengal, India. Int J Pediatr 2014; 2:13-21.

28. Thakur M S, Naik JD, Jailkhani SMK et al. Anthropometric Assessment and Morbidity Profile of under Five Children Attending Immunization Clinic at Urban Health Centre. Sch J App Med Sci 2014; 2(1C): 352-6. 